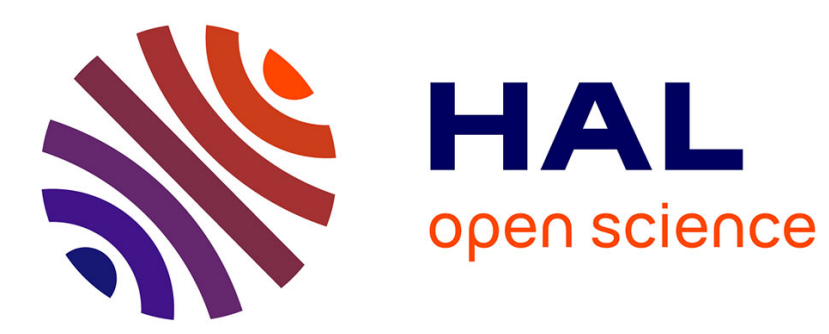

\title{
Group Additivity for Aqueous Phase Thermochemical Properties of Alcohols on $\mathrm{Pt}(111)$
}

Geun Ho Gu, Benjamin Schweitzer, Carine Michel, Stephan N. Steinmann, Philippe Sautet, Dionisios G. Vlachos

\section{- To cite this version:}

Geun Ho Gu, Benjamin Schweitzer, Carine Michel, Stephan N. Steinmann, Philippe Sautet, et al.. Group Additivity for Aqueous Phase Thermochemical Properties of Alcohols on Pt(111). Journal of Physical Chemistry C, 2017, 121 (39), pp.21510 - 21519. 10.1021/acs.jpcc.7b07340 . hal-01641026

\author{
HAL Id: hal-01641026 \\ https://hal.science/hal-01641026
}

Submitted on 24 Mar 2019

HAL is a multi-disciplinary open access archive for the deposit and dissemination of scientific research documents, whether they are published or not. The documents may come from teaching and research institutions in France or abroad, or from public or private research centers.
L'archive ouverte pluridisciplinaire HAL, est destinée au dépôt et à la diffusion de documents scientifiques de niveau recherche, publiés ou non, émanant des établissements d'enseignement et de recherche français ou étrangers, des laboratoires publics ou privés. 


\title{
Group Additivity for Aqueous Phase Thermochemical Properties of Alcohols on Pt(111)
}

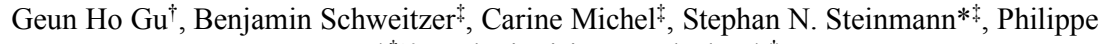 \\ Sautet*\$\&\&, and Dionisios G. Vlachos*,† \\ $\dagger$ Department of Chemical and Biomolecular Engineering, Catalysis Center for Energy Innovation, University of \\ Delaware, Newark, DE 19716, U.S.A. \\ * Univ Lyon, ENS de Lyon, CNRS, Université Lyon 1, Laboratoire de Chimie UMR 5182, F-69342, Lyon, \\ France \\ $\S$ Department of Chemical and Biomolecular Engineering, University of California, Los Angeles, Los Angeles, \\ CA 90095, U.S.A \\ ${ }^{\&}$ Department of Chemistry and Biochemistry, University of California, Los Angeles, Los Angeles, CA 90095 , \\ U.S.A.
}

\begin{abstract}
Despite progress in theoretical tools, the influence of solvation in heterogeneous catalysis remains poorly understood and predicted due to the large computational burden. In this work, we show that the inclusion of the solvation by water using a continuum model thermodynamically inhibits the $\mathrm{OH}$ bond scissions involved in the ethanol aqueous phase reforming reaction over $\mathrm{Pt}(111)$, while it tends to favor the $\mathrm{CH}, \mathrm{CC}$ and $\mathrm{CO}$ scissions. Then, we present a novel group additivity scheme for the free energy of adsorbates at the Pt /water interface that is able to capture this solvent effect. The mean absolute error (MeanAE) for the Gibbs free energy of formation is 3.3 $\mathrm{kcal} / \mathrm{mol}$ over the investigated set of 200 species at the interface and the MeanAE for the 151 reaction free energies of ethanol aqueous phase reforming is $2.8 \mathrm{kcal} / \mathrm{mol}$. Regarding the effect of solvation, our scheme is able to predict it with a MeanAE of about $1 \mathrm{kcal} / \mathrm{mol}$. Together, the scheme promises to be accurate enough for narrowing down the most important reaction pathways in complex reaction networks as encountered in biomass conversion.
\end{abstract}




\section{INTRODUCTION}

Biomass processing occurs often in water. Aqueous phase reforming is one of the processes and converts polyols and sugars in water to $\mathrm{H}_{2}$ and $\mathrm{CO}_{2}$ at relatively low temperatures under pressure, as popularized by Dumesic and co-workers. ${ }^{1}$ An alternative large scale use of biomass conversion is bio-oil production via pyrolysis, which contains $15-30 \%$ water $^{2}$, and needs to be further upgraded via hydrodeoxygenation. Here solvation effects are important due to the deactivation of well-studied NiMo sulphides in aqueous environment. ${ }^{3}$ Another alternative is the selective transformation of sugar derivatives to largely used monomers such as acrylic or adipic acid. ${ }^{4,5}$ All of these processes involve hydrogenations, C-C and $\mathrm{C}-\mathrm{OH}$ bond breakings in the presence of water, which imposes different conditions than for the current petro-chemistry. As demonstrated by several experimental studies, the presence of water is not innocent, even beyond catalyst stability, driving the need for new catalytic systems. ${ }^{6-9}$

The difference between chemistry in the gas- and solution-phase can be dissected into several distinct effects: (1) solubility influences the concentration of reactants, intermediates and products and hence impacts the kinetics even if the rate constants would not change compared to the gas-phase ; (2) the solvent can participate directly in the reaction, either as a reactant or as co-catalyst (e.g., in relay mechanisms of proton transfers); (3) the averaged interaction between the solvent and the solute changes the energetics compared to the gas-phase, stabilizing large dipole moments and charge-separations (heterolytic bond dissociations); (4) entropic contributions arise as the available phase-space can be significantly different in solution compared to the gas-phase, both in terms of translation/rotations and accessible configurations; and (5) the occurrence of homogeneous reactions in solvent phase such as dehydration and aldol condensation. ${ }^{10}$

Despite the wide use of solvent in biomass conversion, only a limited number of theoretical studies have explicitly addressed solvation effects. ${ }^{11-19}$ This shortcoming is due to the methodology: there are no computationally affordable, broadly validated and general methods to include solvent effects in heterogeneous catalysis. The most rigorous way to describe reactivity in condensed phases is to perform thermodynamic integration at the $a b$ initio molecular dynamics (AIMD) level. ${ }^{20,21}$ However, these computations are prohibitively expensive, as equilibration of the solid-liquid interface and convergence of the free energy would require more than $100 \mathrm{ps}$ of simulations, ${ }^{22}$ but todays computing power only allows to obtain about $10 \mathrm{ps}$ for metallic surfaces with a reasonable effort. ${ }^{23}$ Therefore, different approximations have been proposed: inclusion of only a couple of solvent molecules (called micro-solvation) ${ }^{24,25}$, adsorption of ice-like water layers on metallic surfaces ${ }^{26,27}$, the use of a combination of optimization and AIMD, ${ }^{11,18,19}$ the classical treatment of solvent interactions ${ }^{16,28}$ or the application of implicit solvent models. ${ }^{29-31}$ In terms of accessible and interpretable differences between gas-phase and solution-phase reactivity, the advantage of implicit solvents is that solvation energies are directly accessible, which is not the case for AIMD simulations. On the other hand, the main limitation of implicit solvents is that no direct participation of the solvent can be described, in contrast to micro-solvation approaches. As a compromise between efficiency and general accuracy, the combination of an implicit solvent with micro-solvation has been explored..$^{25,32-35}$

The main conclusions of the various theoretical studies are that adsorbate bindings are weaker in solution than in gas-phase given that the surface needs to be desolvated and only roughly half of the adsorbate is exposed to the solvent. ${ }^{13}$ Second, reaction barriers are minimally affected, except for proton transfers for which water can act as a relay or at least activates $\mathrm{O}-\mathrm{H}$ bonds ${ }^{25}$ 
and when hydroxyl groups get well-exposed to the solvent in the course of the elementary step. ${ }^{12,28}$ As a minor variant, elementary steps that drastically change the surface dipole moment are also influenced by the solvent. ${ }^{12,14}$ This phenomenon can, in the case of acidic protons, lead to heterolytic bond breakings at the water/metal interface. ${ }^{24}$ Furthermore, solvent effects are critical when surfaces are partially charged, either in electrochemistry ${ }^{36}$ or when assessing the influence of a base which promotes the reaction through co-adsorption. ${ }^{37}$ Despite these progress, investigation of the effect of solvent on the entire reaction networks using density functional theory (DFT) remains challenging due to the tremendous computational burden, especially for large alcohols and polyols. ${ }^{38}$

Previously, group contribution methods were pioneered by Benson to predict thermodynamic properties of molecules at a greatly reduced computational cost. ${ }^{39}$ Those methods use molecular fragments to correlate thermodynamic properties. The simplest form is to estimate the property of a given component as the sum of its molecular fragments or groups and is simply called group additivity. ${ }^{39}$ It is based on the observation that state properties of molecules can be expressed as simple sums over values assigned to the functional groups. As an example, elongating a linear alkane by one additional methylene $\left(\mathrm{CH}_{2}\right)$ group decreases the heat of formation of the alkane by $\sim 5 \mathrm{kcal} / \mathrm{mol}$. This simple picture can be refined by applying various corrections for neighboring groups. Nevertheless, the property evaluations are extremely simple compared to quantum mechanical computations. This method was initially developed for closed-shell gas molecules, ${ }^{39-}$ ${ }^{41}$ and has since been extended to open-shell radicals, ${ }^{42}$ transition states, ${ }^{43,44}$ and carbenium ions. ${ }^{45}$ Additionally, group additivity has been applied to pure liquids and dilute solutes, ${ }^{46}$ and it has been shown to accurately predict various state properties such as the volume, density, viscosity, boiling point, melting point, critical temperature, and pressure. ${ }^{47-50}$

The group additivity scheme accounts for intra-molecular interactions, whereas solution nonideality requires inclusion of inter-molecular interactions, whose strength depends on the composition of the mixture. To address this issue, group contribution methods that include group interactions were developed. For instance, universal quasichemical functional-group activity coefficients (UNIFAC), ${ }^{51,52}$ computes the average interaction between groups using FloryHuggins statistical-mechanics model. This method employs the surface area and volume of each group, in addition to the interactions between groups as descriptors, which are then correlated to activity coefficients. More recently, the group contribution method has been extended to equations of state, with the statistical associating fluid theory (SAFT) and conductor-like screening model-segment activity coefficient (COSMO-SAC) models demonstrating promising performance $^{53,54}$ These methods apply to bulk fluid mixtures but do not consider catalyst surfaces. The Delaware group has been developing group contribution methods ${ }^{55}$ to predict adsorbate properties for hydrocarbons, oxygenates, furanics and aromatics, ${ }^{56-58}$ which, combined with linear scaling relationships, can predict thermochemistry on metal surfaces. ${ }^{59,60}$ However, such a group additivity method for the prediction of thermodynamic properties of adsorbates in the presence of a solvent has yet to be developed.

In this paper, we demonstrate that the introduction of an implicit solvent changes the reaction equilibrium constants of specific reaction types (e.g., C-H and $\mathrm{O}-\mathrm{H}$ dissociations). Then, we build a group additivity method for Gibbs free energy of formation of linear alcohol adsorbates in vacuum and solvent using the polarizable continuum method (PCM) and the previous group additivity scheme. ${ }^{29,56}$ Cross-validation reveals that the mean absolute error (MeanAE) is 1.03 $\mathrm{kcal} / \mathrm{mol}$ and $3.33 \mathrm{kcal} / \mathrm{mol}$ for the solvation free energy and the Gibbs free energy of formation, 
respectively. We further assess our model by comparing DFT computed reaction energies to those predicted via group additivity.

\section{METHODS}

Density Functional Theory and Polarizable Continuum Model. The DFT computations are carried out with the Vienna Ab initio Simulation Package VASP 5.3.5 ${ }^{61}$. The electronic structure is described within the generalized gradient approximation using the $\mathrm{PBE}^{62}$ exchange correlation functional. The dispersion correction is included using the $\mathrm{dDsC}$ approach. ${ }^{63,64}$ The projector augmented wave method (PAW) is used to describe the ion-electron interactions. ${ }^{65,66}$ The plane wave basis set is cut off at $400 \mathrm{eV}$. The electronic energy is converged to $10^{-6} \mathrm{eV}$ and the forces to $0.02 \mathrm{eV} \AA^{-1}$. The solvation is described using an implicit solvation model as implemented in the package VASPsol. ${ }^{29,67}$ Dipole correction in the $\mathrm{z}$ direction is applied for adsorbates to avoid periodic summation of induced dipole and solvent model effect. ${ }^{16}$

The platinum surface is simulated as a $\mathrm{p}(4 \mathrm{x} 4)$ slab consisting of four layers. The two bottom layers are kept fixed at the optimal bulk position in which the Pt-Pt distance is $2.80 \AA$. The vacuum distance is large enough to avoid spurious interactions (the norm of the vector perpendicular to the surface is $22.86 \AA$ ). The integration of the Brillouin zone is performed using a Monkhorst-Pack mesh of with 3 x 3 x 1 k-points for surfaces. The gas phase calculations are done at the gamma point in a cubic box of $20 \AA$ in length.

Thermodynamic Property Calculations of Molecules. The Gibbs free energy of formation of a species $i$ in gas-phae, $\Delta G_{\mathrm{f}, i_{(\mathrm{gp})}}$, is:

$$
\Delta G_{\mathrm{f}, i_{(\mathrm{gp})}}=\Delta H_{\mathrm{f}, i_{(\mathrm{gp})}}-T S_{i_{(\mathrm{gp})}}
$$

where $\Delta H_{\mathrm{f}, i_{(\mathrm{gp})}}$ is the enthalpy of formation of the molecule $i$ in gas-phase, and $T$ is the temperature, and $S_{i_{(\mathrm{gp})}}$ is the entropy of the species $i$ in gas-phase computed using statistical mechanics, atoms' coordinates and vibrational frequencies (See ref ${ }^{57}$ for detail). We consider two type of species $i$ : a gaseous molecule and an adsorbate. $\Delta H_{\mathrm{f}, i_{(\mathrm{gp})}}$ is estimated as:

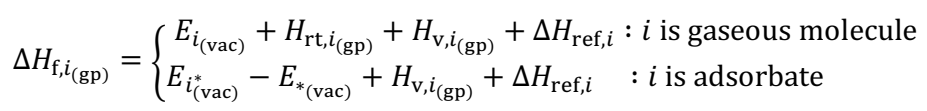

where $E_{i_{\text {(vac })}}$ is the DFT electronic energy of the gaseous species $i$ in vacuum, $E_{i^{*} \text { (vac) }}$ is the DFT

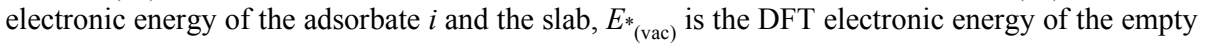

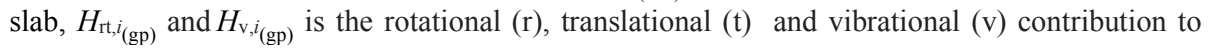
the heat of formation for the species $i$ computed in the gas-phase, respectively (See $\operatorname{ref}^{57}$ for calculation detail). For a strongly bounded adsorbate, the rotational and translational degrees of freedom of atomic motion become vibrational upon binding, thus ${H^{\circ}}_{\mathrm{rt}, i \mathrm{(gp})}$ does not exist for adsorbate. To change from DFT reference system (infinitely separated atoms and electrons) to conventional heat of formations, we introduce the adjustment $\Delta H_{\mathrm{ref}, i}$ (see $\operatorname{ref}^{57,60}$ for computational details and the supplementary materials for the structures and properties of reference molecules). For the computation of the Gibbs free energy of formation of a solute $i$ in 
water or an adsorbate $i$ in water/metal interface $\left(\Delta G_{\left.\mathrm{f}, i_{(\mathrm{aq}}\right)}^{\circ}\right.$, we assume that solvation does not depend on temperature (see SI for further discussion) and that the entropy of a species is the same in gas-phase and water. In particular the later approximation is rather severe for adsorption from the liquid phase on the catalyst: Although for ideal solutions the entropy of a solute is the same as the one in the corresponding gas-phase when appropriately taking into account the available volume, ${ }^{68,69}$ the entropy in aqueous solution for real solutes differs by roughly a factor two. ${ }^{10,70}$ Since an adsorbate competes with the solvent for adsorption sites, the entropy of the adsorbate is, in general, even more challenging to assess than the entropy in solution. Although the structure of the solid-liquid interface remains a matter of debate, it is well established that the solvent properties at the interface are different compared to the bulk liquid. ${ }^{71-74}$ Determining the change in entropy upon adsorption requires large-scale molecular dynamics simulations, which are difficult to converge, both in terms of size and timescale. ${ }^{73,75-77}$ While AIMD would be ideal for such studies, the corresponding computational effort is tremendous. ${ }^{74,78-80}$ On the other hand, force field methods, which make such investigations affordable, ${ }^{81,82}$ suffer from low availability for general interfaces and very limited accuracy, best exemplified for the seemingly trivial watermetal interface, for which many potentials exist, ${ }^{21,78,83,84}$ but only for the case of $\mathrm{Cu} / \mathrm{H}_{2} \mathrm{O}$ there exists a well validated force field. ${ }^{76}$ Due to all these considerations, the simplistic approximation taken herein makes our approach transparent and, once established, the corresponding entropy corrections can be trivially applied to our model. Hence, $\Delta G_{\mathrm{f}, i_{(\mathrm{aq})}}$ is:

$$
\begin{aligned}
& \Delta G_{\mathrm{f}, i_{(\mathrm{aq})}}=\Delta H_{\mathrm{f}, i_{(\mathrm{aq})}}-T S_{i_{(\mathrm{aq})}} \\
& S_{i_{(\mathrm{aq})}} \cong S_{i_{(\mathrm{gp})}}
\end{aligned}
$$

where $\Delta H_{\mathrm{f}, i_{(\mathrm{aq})}}$ and $S_{i_{(\mathrm{aq})}}$ are the enthalpy of formation and the entropy of species $i$ in aqueous solvent, respectively. The effect of the implicit solvation is included in $\Delta H_{\mathrm{f}, i_{(\mathrm{aq})}}$ as the change in electronic energy:

$$
\begin{aligned}
& \Delta H_{\mathrm{f}, i_{(\mathrm{aq})}}=\Delta H_{\mathrm{f}, i_{(\mathrm{gp})}}+E_{\mathrm{sol}, i}+E_{\mathrm{cav}, i} \\
& E_{\mathrm{sol}, i}= \begin{cases}E_{i_{(\mathrm{aq})}}-E_{i_{(\mathrm{vac})}} & : i \text { is gaseous molecule or solute } \\
\left(E_{i *_{(\mathrm{aq})}}-E_{i_{(\mathrm{vac})}^{*}}^{*}-\left(E_{*_{(\mathrm{aq})}}-E_{*_{(\mathrm{vac})}}\right): i\right. \text { is adsorbate }\end{cases}
\end{aligned}
$$

where $E_{\mathrm{sol}, i}$ is the solvation electronic energy of a species $i, E_{i_{(\mathrm{aq})}}$ is the DFT electronic energy of the solute $i$ in implicit water, $E_{i^{*} \text { (aq) }}$ is the electronic energy of the solvated adsorbate $i$ and the

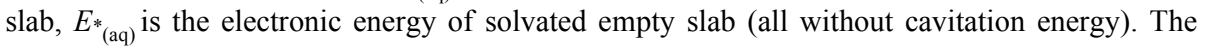
cavitation energy approximates the energetic cost to insert a solute in a solvent, such as solvent reorganization and (Pauli) repulsion. Its energy is usually assumed to be proportional to the solvent accessible surface area. We introduce an empirical cavitation energy correction term, $E_{\mathrm{cav}, i}$. The computation of cavitation energy using PCM is difficult for the adsorbates and the slab due to numerical instability. Instead, we compute cavitation energy for a small subset of our data, and regress the cavitation energy contribution for each element. The computation of $E_{\mathrm{cav}, i}$ is discussed below in detail. The Gibbs free energy of solvation of a species $i$ initially in gas-phase, 
$\Delta G_{\text {sol, }, i}^{\circ}$ is the Gibbs free energy to transfer a species $i$ from the gas-phase to the liquid bulk, which, using the equation above, is:

$$
\Delta G_{\mathrm{sol}, i}=\Delta G_{\mathrm{f}, i_{(\mathrm{aq})}}-\Delta G_{\mathrm{f}, i_{(\mathrm{vac})}}=E_{\mathrm{sol}, i}+E_{\mathrm{cav}, i}
$$

The accuracy of the PCM is further assessed in Figure S1 in SI, where the DFT-computed values of $\Delta G_{\text {sol }, i}$ are in a good agreement with the experimental $\Delta G_{\text {sol }, i}$ at $298 \mathrm{~K}$, with a mean absolute deviation of $1.1 \mathrm{kcal} / \mathrm{mol}$. Unfortunately, such data is not available for species at the interface. Hence, the accuracy of the herein applied PCM cannot be assessed. Furthermore, computationally feasible alternatives to implicit solvents to produce a consistent set of undoubtedly reliable solvation free energies at the interface are, to the best of our knowledge, not yet available. More reliable solvation free energies could be obtained with an accurate force field $^{16}$ or with long-time-scale ab initio molecular dynamics simulations; in the first case, the force field is currently missing and in the second option is not yet computationally affordable.

In addition to the heat of formation and entropy, we also compute the heat capacity at any temperature $T$ for the species $i, C_{\mathrm{P}, T, i_{(\mathrm{gp})}}\left(C_{\mathrm{P}, T, i_{(\mathrm{aq})}} \cong C_{\mathrm{P}, T, i_{(\mathrm{gp})}}\right.$; See ref ${ }^{57}$ for calculation detail) for the group additivity regression in order to transfer properties to different temperatures. We surveyed $C_{\mathrm{P}, T, i_{(\mathrm{gp})}}$ between 100 to $1500 \mathrm{~K}$ at $100 \mathrm{~K}$ intervals. Figure 1 summarizes the relationship between gaseous molecules, molecule in the bulk liquid, adsorbates, and solvated adsorbates in a thermodynamic cycle.

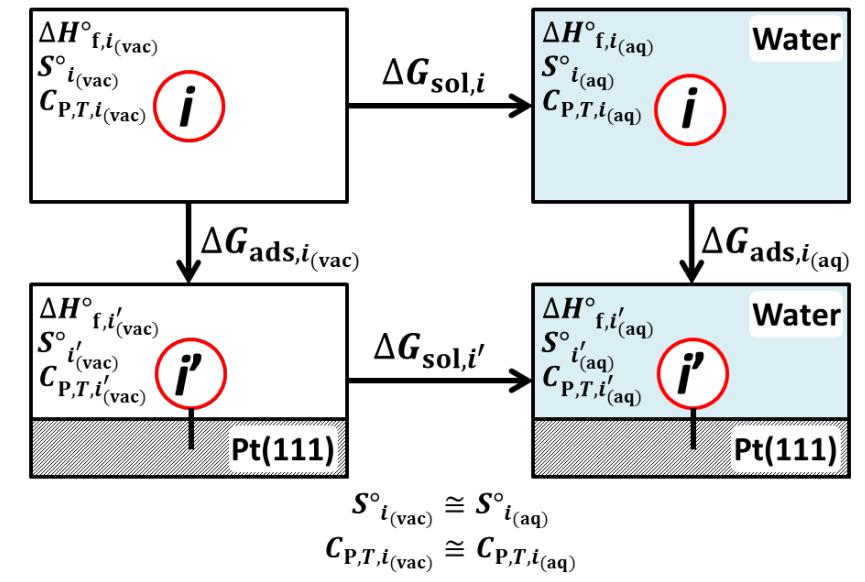

Figure 1. Various considered states for the system, summarized in a thermodynamic cycle. $i$ is an arbitrary species, and $i$ ' is the species $i$ adsorbed on the surface. Boxes represents a molecule in the gaseous state, in the bulk liquid, adsorbed on $\mathrm{Pt}(111)$, and adsorbed and solvated on $\mathrm{Pt}(111)$ going from left to right and from top to bottom. The three thermodynamic properties in each box represent the parameters predicted by our method. We assume that the solvation effect is temperature independent, thus the entropy and heat capacity are the same in vacuum and in water.

Group Additivity. The group additivity method assumes that a thermodynamic property, $\Phi$, is a linear combination of the thermodynamic properties of groups found within a molecule, 


$$
\Phi_{i}=\sum_{j=1}^{N_{\text {groups }}} n_{i j} \varphi_{j}
$$

where $n_{i j}$ is the number of times group $j$ appears in a species $i$ and $\varphi_{j}$ is group $j$ 's contribution to the thermodynamic properties. $\varphi_{j}$ values can be derived via linear regression of experimental data or quantum chemical calculations (vide infra).

Conventionally, the linear regression is performed for three thermodynamic properties: standard heat of formation, standard entropy, and, heat capacity at temperature $T .{ }^{39,42}$ To account for the solvation effect, we perform the regression to one additional property, standard heat of formation of solvated species. In order to perform regression to properties of both gaseous molecules and adsorbate molecules together, we found that subtracting rotational and translational contribution from the heat of formation of gaseous molecules improves the fitting. ${ }^{56,57,59}$ Hence, the dependent variables for the regression are:

$$
\begin{aligned}
& \Delta H_{\mathrm{f}, i_{(\mathrm{gp})}, \mathrm{GA}}= \begin{cases}\Delta H_{\mathrm{f}, i_{(\mathrm{gp})}}-H_{\mathrm{rt}, i_{(\mathrm{gp})}} & : i \text { is gaseous molecule } \\
\Delta H_{\mathrm{f}, i_{(\mathrm{gp})}} & : i \text { is adsorbate }\end{cases} \\
& \Delta H_{\mathrm{f}, i_{(\mathrm{aq})}, \mathrm{GA}}= \begin{cases}\Delta H_{\mathrm{f}, i_{(\mathrm{aq})}}-H_{\mathrm{rt}, i_{(\mathrm{vac})}} & : i \text { is gaseous molecule or solute } \\
\Delta H_{\mathrm{f}, i_{(\mathrm{aq})}} & : i \text { is adsorbate }\end{cases} \\
& C_{\mathrm{P}, T, i_{(\mathrm{gp})}, \mathrm{GA}}= \begin{cases}C_{\mathrm{P}, T, i_{(\mathrm{gp})}}-C_{\mathrm{P}, T, \mathrm{rt}, i_{(\mathrm{gp})}}: i \text { is gaseous molecule } \\
C_{\mathrm{P}, T, i_{(\mathrm{gp})}}: i \text { is adsorbate }\end{cases}
\end{aligned}
$$

where the subscript "GA" represents the part of the quantity which is expressed in terms of a group additivity scheme. $C_{\mathrm{P}, T, \mathrm{rt}, i_{(\mathrm{gp})}}$ is rotational and translational contribution to the heat capacity. For the entropy, we do not correct for rotational and translational contribution but correct for the symmetric number $(\sigma)$ contribution following Bensons' group additivity formulation ${ }^{39}$ :

$$
S_{i_{(\mathrm{gp}), \mathrm{GA}}}= \begin{cases}S_{i_{(\mathrm{gp})}}+\ln (\sigma): i \text { is gaseous molecule } \\ S_{i_{(\mathrm{gp})}}: i \text { is adsorbate }\end{cases}
$$

We assume that there is no symmetry contribution for adsorbates. The rotational and translational corrections are only applied to the heat of formation and heat capacity as the rotational and translational contributions do not depend on the groups, but are a constant shift (e.g. $H_{\mathrm{rt}, i_{(\mathrm{gp})}}=C_{\mathrm{P}, \mathrm{rt}, i_{\text {(gp })}}=4 \mathrm{R} T$ for non-linear molecules, or ${ }^{7} / 2 \mathrm{R} T$ for linear molecules). However, the rotational and translational corrections for entropy depend on the atoms' weight and coordinates, and hence group additivity approach can describe these terms. For the computation of gaseous molecule properties, these subtracted terms needed to be added back after using group additivity.

The group additivity parameters, $\boldsymbol{\varphi}_{(N \times 1)}$, are computed using Moore-Penrose pseudoinverse indicated by ${ }^{+}$and using linear regression:

$$
\boldsymbol{\varphi}=\left(\boldsymbol{n}^{T} \boldsymbol{n}\right)^{+} \boldsymbol{n}^{T} \boldsymbol{\Phi}
$$

where $N$ is the number of groups, and $\boldsymbol{n}_{(M \times N)}$ is the group contribution matrix, and $M$ is the number of data points, and $\boldsymbol{\Phi}_{(M \times 1)}$ is the vector of thermodynamic parameters. The predictive 
accuracy of the model is assessed using $k$-fold cross validation. ${ }^{85,86}$ In this method, the data set is randomly partitioned into $k$ subsamples of equal size. The model is trained using $k-1$ subsamples, and the remaining subsample is used as the validation set to compute the model error. This process is repeated $k$ times with each subsample used as a validation set once. Since the data partitioning involves randomization, Monte Carlo sampling is employed to compute the average error of each molecule. We used 10 as the value of $k$ and 1000 repetitions of random partitioning which results in $95 \%$ confidence interval of predicted values less than $0.1 \mathrm{kcal} / \mathrm{mol}$ for

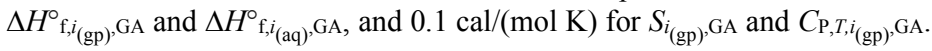

Training Set. Our training set consists of 200 data points that are divided into three subcategories: (i) 27 gas molecules, (ii) 53 adsorbates found in the ethanol aqueous phase reforming reaction network, and (iii) 110 adsorbates and 10 gas molecules from the butane-tetra-ol reaction network. ${ }^{87}$ The adsorbates in the ethanol reaction network include the dissociation products of ethanol as well as species from the water-gas-shift reaction and are used to examine the solvation effect on the reaction energies. The adsorbates from the reaction network of butane-tetra-ol supplement the poly-ol backbone of our group-additivity scheme. This reaction network, generated using the R.I.N.G. software package, ${ }^{88,89}$ contains a total of 5374 species, of which 120 species have been chosen randomly under the constraint that each non-unique group is found in at least 7 points of the complete training set. The gas molecules are computed to test the effect of the PCM on the vibrational frequencies (see Figure S2 in the SI). The computed thermodynamic properties and structures of the training set species are also provided in the SI.

Cavitation Energy Corrections. The cavitation energy corrections introduced above, $E_{\mathrm{cav}, i}$, corrects the thermodynamic properties computed using DFT calculations without the cavitation energy. To compute the corrections, we obtained cavitation energies, $E_{\mathrm{cav}, i}$, of 20 solutes and 9 solvated adsorbates using equation below:

$$
E_{\mathrm{cav}, i}=E_{\mathrm{sol}, i,+c}-E_{\mathrm{sol}, i,-c}
$$

where $E_{\mathrm{sol}, i,+\mathrm{c}}$ and $E_{\mathrm{sol}, i, \mathrm{c}}$ are $E_{\mathrm{sol}, i}$ using equation (5), with the cavitation energy accounted and unaccounted, respectively. $E_{\mathrm{sol}, i+\mathrm{c}}$ is computed using energy cut off of $600 \mathrm{eV}$ to improve the accuracy of this numerically delicate quantity. In a similar spirit to group additivity, we perform a regression of cavitation contribution for each element $(\mathrm{C}, \mathrm{H}, \mathrm{O})$ to 29 data:

$$
E_{\mathrm{cav}, i}=\sum_{j}^{\mathrm{C}, \mathrm{H}, \mathrm{O}} n_{i j} e_{\mathrm{cav}, j}
$$

where $n_{i j}$ is the number of occurrence of element $j$ in species $i$, and $e_{\text {cav }, j}$ is the cavitation energy of element $j$ computed using the linear regression method introduced above. The MeanAE and MaxAE (training error, not cross-validation error) are 0.18 and $0.47 \mathrm{kcal} / \mathrm{mol}$, respectively. The training set data and regression coefficients are provided in SI.

\section{RESULTS AND DISCUSSION}

Having presented the methodological approach, we now turn to the results of our study. First, we discuss the influence of the implicit solvent on geometries and reaction free energies. Then, we present the performance of our group additivity scheme for gas- and solution-phase species and reactions. 
Influence of the solvation on the DFT geometries. Upon solvation by water using a continuum model, isolated molecules showed limited structural changes with a root mean square deviation (RMSD) of $0.02 \AA$ and a maximum RMSD of $0.09 \AA$. The RMSD have been evaluated using the Kabsch algorithm. ${ }^{90-92}$ This algorithm optimally superposes the two molecules to minimize translational and rotational error and computes the RMSD. For the surface species, we disregarded the change in surface atom's position. These small positional changes are induced by the dipolar interactions with the continuum solvent mostly affecting the relative orientation of the C-O bonds. The structures of the adsorbed species are slightly more sensitive to the solvation with a mean RMSD of $0.03 \AA$ and a maximum RMSD of $0.16 \AA$. This maximum corresponds to a change in the orientation of the $\mathrm{OH}$ bonds of $\mathrm{COH}-\mathrm{C}-\mathrm{CH}_{2}-\mathrm{CHOH}$ that rotates from pointing towards the surface to pointing towards the solvent. To better analyze this effect, we considered this reorientation for surface intermediates in the ethanol steam reforming reaction network. While the conformer with the $\mathrm{OH}$ bond pointing down is the most stable in vacuum, pointing the $\mathrm{OH}$ bond up becomes more stable in water. This effect, illustrated in the simple case of the $\mathrm{CHOH}$ fragment in Figure $2_{\mathrm{p}}$ is assigned to a better solvation of the $\mathrm{OH}$ by up 3 to $5 \mathrm{kcal} / \mathrm{mol}$ compared to $\mathrm{OH}$ down.

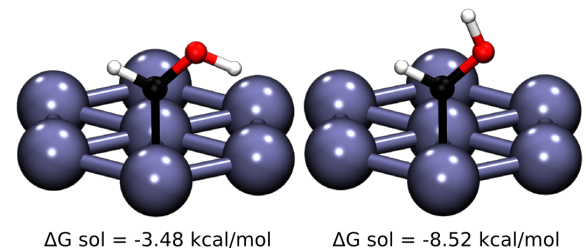

Figure 2. DFT structures of the $\mathrm{HCOH}$ fragment adsorbed on a $\mathrm{Pt}(111)$ slab: (left) the $\mathrm{H}$ down configuration (right) the $\mathrm{H}$ up configuration, and associated solvation energies.

Influence of the solvation on reactions. We assess the influence of PCM on ethanol aqueous reforming, including water-gas shift reactions, by considering the corresponding standard Gibbs free energy of reactions in gas-phase (gp) and solution (aq):

$$
\begin{aligned}
\Delta G_{\mathrm{r},(\mathrm{gp})} & =\sum_{i} v_{i} \Delta G_{\mathrm{f}, i_{(\mathrm{gp})}} \\
\Delta G_{\mathrm{r},(\mathrm{aq})} & =\sum_{i} v_{i} \Delta G_{\mathrm{f}, i_{(\mathrm{aq})}}
\end{aligned}
$$

where the reaction involves species $i$ with the stoichiometric coefficient $v_{i}$ with $v_{i}>0$ if $i$ is a product. To assess the change in the standard Gibbs free energy of reaction upon solvation, we further define $\Lambda_{\text {sol }}$ as the change of a reaction energy upon solvation:

$$
\Lambda_{\mathrm{sol}}=\Delta G_{\mathrm{r},(\mathrm{aq})}-\Delta G_{\mathrm{r},(\mathrm{gp})}
$$

When $\Lambda_{\text {sol }}$ is negative, the reaction is favored by solvation, the Gibbs energy of reaction at the solid-liquid interface being more exergonic than in the gas-phase. This change can also be seen as the sum of the solvation energies of each species $i$ involved in the chemical reaction with a stoichiometric coefficient $v_{i}$ :

\section{Deleted: Figure 2}

Deleted: enhancement factor

Deleted: enhancement factor 


$$
\Lambda_{\mathrm{sol}}=\sum_{i}^{N_{\text {species }}} v_{i} \Delta G_{\mathrm{sol}, i}
$$

$\Lambda_{\text {sol }}$ is reported as a box plot on Figure $3 \mathrm{a}$ for each type of reaction under consideration: adsorption, C-H, O-H, C-C and C-O bond scissions.

In general, the adsorption of close-shell molecules is only slightly disfavored by the solvation with a mean of $0.2 \mathrm{kcal} / \mathrm{mol}$ for $\Lambda_{\text {sol }}$. The most affected species is acetaldehyde with $\Lambda_{\text {sol }}=2.4$ $\mathrm{kcal} / \mathrm{mol}$ : its adsorption at the $\operatorname{Pt}(111)$ surface is disfavored by the stronger solvation in the solution $\left(\Delta G_{\text {sol }}=-5.6 \mathrm{kcal} / \mathrm{mol}\right)$ than at the surface $\left(\Delta G_{\text {sol }}=-3.3 \mathrm{kcal} / \mathrm{mol}\right)$.

Since the solvation energy does not change significantly upon adsorption, the analysis of the solvation energy of different species is done jointly for the molecules in bulk water and the ones adsorbed at the interface. The species have been split into three groups to represent the solvation Gibbs energy $\Delta G_{\text {sol }}$ with box plots in Figure 3b: (1) Hydroxyl contains at least one hydroxyl group, including water; (2) Aprotic Oxygenate includes all the species that contain an oxygen atom but not a hydroxyl group, for instance acetaldehyde (3) Hydrocarbon selects species that do not contain any oxygen atom. As expected, Hydrocarbon members are weakly solvated by water (on average, $\Delta G_{\text {sol }}=-1.7 \mathrm{kcal} / \mathrm{mol}$, standard deviation of $\sigma=1.0 \mathrm{kcal} / \mathrm{mol}$ ). Aprotic Oxygenate are more solvated (on average, $\Delta G_{\text {sol }}=-2.9 \mathrm{kcal} / \mathrm{mol}, \sigma=0.9 \mathrm{kcal} / \mathrm{mol}$ ) with a small standard deviation $(\sigma)$. The Hydroxyl species show a stronger Gibbs solvation energy (on average, $\Delta G^{\circ}{ }_{\text {sol }}$ $=-5.6 \mathrm{kcal} / \mathrm{mol}, \sigma=1.9 \mathrm{kcal} / \mathrm{mol}$ ) and, more importantly, a large standard deviation, with a maximum and minimum of $-2.5 \mathrm{kcal} / \mathrm{mol}$ and $-9.8 \mathrm{kcal} / \mathrm{mol}$, respectively. For the surface species, the strong variations can be directly related to the two possible orientations of the $\mathrm{OH}$ bond, up or down. In most cases, the $\mathrm{OH}$ down is the most stable configuration and is poorly solvated (for instance, $\Delta G^{\circ}$ sol $=-3.5 \mathrm{kcal} / \mathrm{mol}$ in $\mathrm{CHOH}$ ). In some cases, the $\mathrm{OH}$ up is the most stable configuration and is strongly solvated such as in $\mathrm{CCHOH}\left(\Delta G^{\circ}\right.$ sol $=-9.3 \mathrm{kcal} / \mathrm{mol}$, the $u p$ configuration being more stable by $0.3 \mathrm{kcal} / \mathrm{mol}$ ).

While most bond dissociations are made more exergonic by the solvation $\left(\Lambda_{\text {sol }}<0\right)$, the $\mathrm{OH}$ scission is generally disfavored $\left(\Lambda_{\text {sol }}>0\right)$. This $\Lambda_{\text {sol }}$ dependency on the reaction type is in agreement with that computed using the $\Delta G_{\mathrm{r},(\mathrm{gp})}$ and $\Delta G_{\mathrm{r},(\mathrm{aq})}$ reported by Behtash et al. ${ }^{12-14}$ With the loss of the most solvated functional group, the $\mathrm{OH}$ scission leads to a net loss in solvation, explaining why such a reaction is less likely in water than at the metal/gas-phase interface. This thermodynamic observation contrasts with our previous kinetic study using microsolvation, where the $\mathrm{O}-\mathrm{H}$ breaking was found to be slightly accelerated by the presence of a water molecule. ${ }^{93}$ On the other hand, it agrees with the study of Lopez and co-workers, who have employed implicit solvation in combination with some explicit water molecules. ${ }^{94}$ In the absence of a detailed study at an explicit water/Pt(111) interface, it is not possible to assert that one or the other study captures the essential effect. The outliers identified in Figure $3 \mathrm{a}$ correspond to reactions where the solvation effect between reactants and products is the most unbalanced. For instance, the three outliers of the $\mathrm{C}-\mathrm{O}$ scission all correspond to reactions that generate the $\mathrm{OH}$ fragment. Two reactions are strongly disfavored at the water-metal interface, due to a strong solvation of the reactants $\left(\mathrm{CCOH}, \Delta G_{\text {sol }}=-9.8 \mathrm{kcal} / \mathrm{mol}\right.$ and $\left.\mathrm{COH}, \Delta G_{\text {sol }}=-7.9 \mathrm{kcal} / \mathrm{mol}\right)$ that exhibit an $\mathrm{OH}$ bond that is pointing towards the solvent. Conversely, the $\mathrm{CH}_{3} \mathrm{COH}$ fragmentation is favored at the water/Pt interface, since this species is only weakly solvated when adsorbed on $\operatorname{Pt}(111)\left(\Delta G_{\mathrm{sol}}=-2.5 \mathrm{kcal} / \mathrm{mol}\right)$, with a $\mathrm{OH}$ bond that points downward.
Deleted: Figure 3

Formatted: English (US)

Deleted: Figure 3

Formatted: English (US)

Formatted: English (US)

Deleted: Figure 3 
In, summary, most of the steps along the ethanol reforming process are favored by the presence of the water solvent except $\mathrm{OH}$ scission (disfavored) and adsorption (neutral). The solvation Gibbs energy of an adsorbate can be related to the presence of a hydroxyl group and more precisely to its orientation: when an $\mathrm{OH}$ bond points towards the bulk water, the corresponding adsorbate is particularly well solvated. This aspect allows rationalizing and predicting the effect of water on most elementary steps.

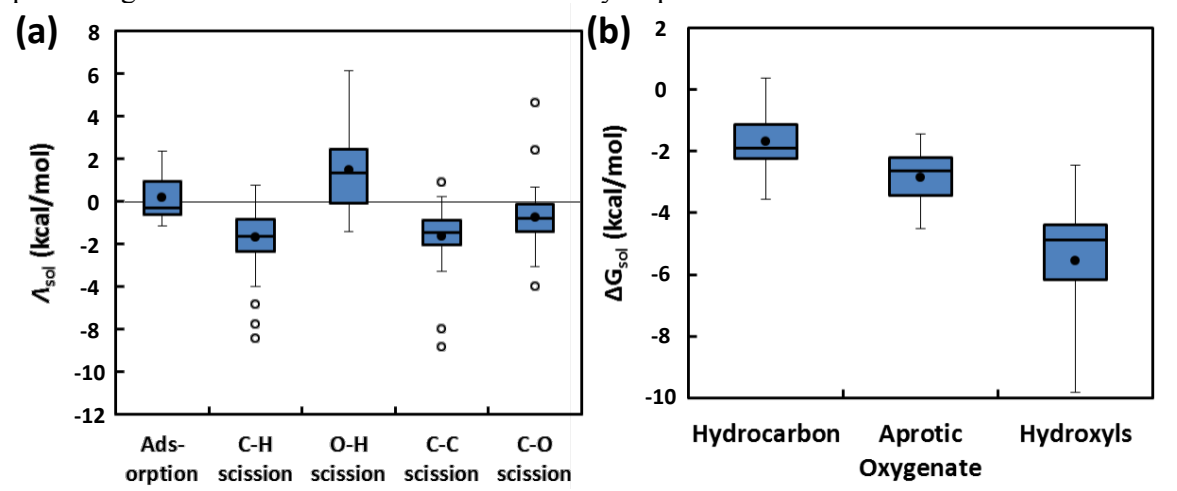

Figure 3. Box plot for the shange of (a) the Gibbs energy of a reaction upon solvation 4 sol (see text for definition) and (b) the solvation Gibbs energy $\Delta G_{\text {sol }}$ of each species using DFT in the ethanol reforming reaction network (without water-gas shift reactions and species). Black dots and white dots represent mean and outliers, respectively. Box represents the second and third quartiles while the whisker represents the first and fourth quartiles. Outliers are at least 1.5 times the box range (between the second and third quartile) from the edge of the box.

Group Additivity Schemes. In this section, we present a group additivity scheme to predict $\Delta G_{\mathrm{f}, i_{(\mathrm{gp})}}$ and $\Delta G_{\mathrm{f}, i_{(\mathrm{aq})}}$. These two quantities are computed using the equations described in the method section. The group additivity scheme for these quantities follows the strategy of Benson's original group additivity. Groups are given as $A(B)_{b}(C)_{c} \ldots$ where $A$ is a group center, and $\mathrm{B}$ and $\mathrm{C}$ are group peripherals, and $\mathrm{b}$ and $\mathrm{c}$ are the numbers of connectivity to the $\mathrm{B}$ and $\mathrm{C}$ group peripherals. A, B, and $\mathrm{C}$ are typically an atom, and sometimes a group of atoms. A, B and $\mathrm{C}$ are further categorized by their hybridization. For example, $\mathrm{C}=$ indicates a carbon with a double bonded neighbor. Also, if the bond order between group center and group peripherals are higher than single bond, the bond order is described (e.g., $\mathrm{A}(=\mathrm{B})$ for $\mathrm{A}$ double bonded to $\mathrm{B}$ ). Every atom must be accounted once as a group center with the exception of hydrogen.

Previously, we have extended this formulation to the adsorbate on surface. ${ }^{56,57,95}$ In these schemes, the valence electrons covalently interacting with the surface electrons are denoted as $(\mathrm{Pt})_{\mathrm{x}}$ group peripheral. For example, the group $\mathrm{C}(\mathrm{H})(\mathrm{Pt})_{2}(\mathrm{O})$ contains a carbon central atom single-bonded to peripheral groups, a hydrogen and an oxygen, and has 2 valence electrons interacting with the surface denoted as $(\mathrm{Pt})_{2}$. This scheme does not distinguish whether the central carbon sits on an atop, bridge, or hollow site; thus, the scheme only requires adsorbates' connectivity to compute their energy. We also adopt ring-strain correction as implemented in a previous study. ${ }^{56}$ These corrections account for the strain of the ring formed by surface atoms and adsorbate atoms. For example, a ring is formed when two connected carbons are bonded to two surface atoms, forming Pt-C-C-Pt ring where two Pt atoms are connected. Additionally, we introduce 16 pair corrections that describe the valence electrons of pairs of central atoms, e.g., 
$\mathrm{C}(\mathrm{Pt})_{3} \mathrm{C}(\mathrm{Pt})_{3}, \mathrm{C}(\mathrm{Pt})_{3} \mathrm{C}(\mathrm{Pt})_{2}, \mathrm{C}(\mathrm{Pt})_{3} \mathrm{C}(\mathrm{Pt}), \mathrm{C}(\mathrm{Pt})_{2} \mathrm{C}(\mathrm{Pt})_{2}$, and so on. These corrections accounts for the partial $\pi$-mode interaction between the two surface-bound organic atoms. Previous studies ${ }^{58,96}$ have shown that, when two connected atoms are bonded to surface, the bond between two connected atoms remains partially conjugated whereas we previously assumed that the bond between two atoms are single bonds. These inadequately defined bond order causes error as the group additivity relies on transferable electron spatial density profile of the homologous groups between molecules. Thus, groups accounting for conjugation are essential to the group additivity scheme. ${ }^{58}$ These corrections improve the model significantly (reduce the MeanAE in $\Delta G_{\mathrm{f},(\mathrm{gp})}$ from 4.6 to $3.3 \mathrm{kcal} / \mathrm{mol}$ using 10 -fold cross-validation). Additionally, we add a group specific to an outlier, $\mathrm{CCOH}$. $\mathrm{CCOH}$ has a unique structure that leads to high deviation for $\Delta G_{\text {sol. }}$ This correction improves the MaxAE of $\Delta G_{\text {sol }}$ from 6.4 to $5.3 \mathrm{kcal} / \mathrm{mol}$.

Following the formulation described above, the model results in total of 82 groups/corrections. The effective rank of this model is 75, i.e., it is rank-deficient. Five of seven linearly dependent descriptors are $\mathrm{C}(\mathrm{Pt})_{3} \mathrm{C}(\mathrm{Pt})_{3}, \mathrm{OC}, \mathrm{OC}(\mathrm{Pt})_{1}, \mathrm{OC}(\mathrm{Pt})_{2}$, and $\mathrm{OC}(\mathrm{Pt})_{3}$ which are part of the new corrections introduced in this work. Since these corrections are already implicitly accounted by the scheme, we remove these corrections. The last two rank deficiency comes from $\mathrm{C}=(\mathrm{CO})(\mathrm{C}=)(\mathrm{H})$ group's dependence to $\mathrm{CO}(\mathrm{C}=)(\mathrm{H})$, and $\mathrm{O}(\mathrm{CO})(\mathrm{H})$ group's dependence to $\mathrm{CO}(\mathrm{O})(\mathrm{Pt})$ (determined using reduced row echelon form). These groups are found in gas/solute molecules, which are not the focus of this study, and the related methods have been previously developed extensively, thus we combine these groups together as a single multi-group. The list of group centers and peripherals as well as corrections and unique groups are summarized in Table 1 and their values are listed in SI.

Table 1. List of group centers and peripherals that constitute groups (See manuscript for group description), corrections and unique groups.

\begin{tabular}{lll} 
Group Centers & Group Peripherals & Corrections/Outlier Correction \\
$\mathrm{C}$ & $\mathrm{C}$ & Corrections: \\
$\mathrm{CO}^{\mathrm{a}}$ & $\mathrm{CO}^{\mathrm{a}}$ & $\mathrm{C}(\mathrm{Pt})_{\mathrm{x}} \mathrm{C}(\mathrm{Pt})_{\mathrm{x}}$ \\
$\mathrm{O}$ & $\mathrm{O}$ & $\mathrm{C}(\mathrm{Pt})_{\mathrm{x}} \mathrm{O}(\mathrm{Pt})_{\mathrm{x}}$ \\
$\mathrm{C}_{=}$ & $\mathrm{C}_{=}$ & $(5$ linearly dependent corrections removed) \\
$\mathrm{C}_{\equiv}$ & $\mathrm{C}_{\equiv}$ & Surface ring strain \\
& $\mathrm{H}$ & \\
& $\mathrm{Pt}$ & Outlier Correction: \\
& & CCOH (Chemisorbed) \\
\hline
\end{tabular}

${ }^{\mathrm{a}} \mathrm{CO}$ indicates $\mathrm{C}=\mathrm{O}$ carbonyl group.

Model Validation. The predictive accuracy of the group additivity model is assessed using $k$ fold cross validation as described in the computational details. ${ }^{85,86}$ Figure $4 \mathrm{a}$ and b show the average of predicted values using the group additivity models vs. the DFT computed $\Delta G_{\mathrm{f},(\mathrm{gp})}$ and $\Delta G_{\text {sol }}$. Cross validation reveals a reasonable MeanAE in $\Delta G_{\mathrm{f},(\mathrm{gp})}$ of $3.3 \mathrm{kcal} / \mathrm{mol}$, and the MaxAE of $16.5 \mathrm{kcal} / \mathrm{mol}$ as shown in Table 2. The large errors are attributed to unaccounted binding modes (e.g., adsorption conformation of polyols). Our previous group additivity model has shown that including binding modes' information to the group descriptors results in large improvement of the cross-validation error. ${ }^{58}$ However, including these unaccounted binding modes requires a significantly larger data set. Since the main utility of the group additivity is to
Deleted: Table 1

Formatted: English (US)

Deleted: Figure 4

Formatted: English (US)

Deleted: Table 2 
rapidly screen large reaction networks before computing the most promising intermediates at the DFT level, a huge computational effort is not justified. The MeanAE and MaxAE for $\Delta G_{\text {sol }}$ are as small as 1.0 and $5.4 \mathrm{kcal} / \mathrm{mol}$, respectively. Importantly, the MeanAE is within chemical accuracy; therefore, the solvation free energy scheme from group additivity provides a good first approximation to estimate the thermochemistry.

(a)

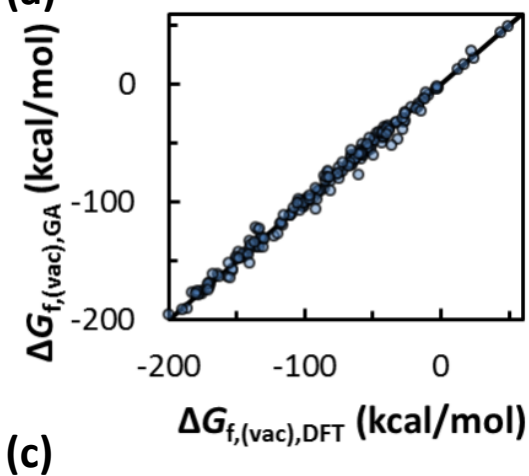

(c)

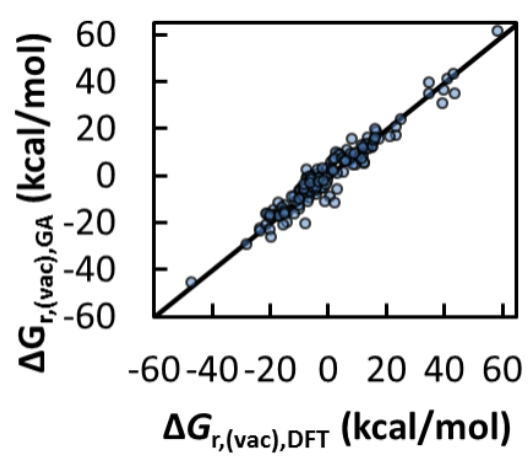

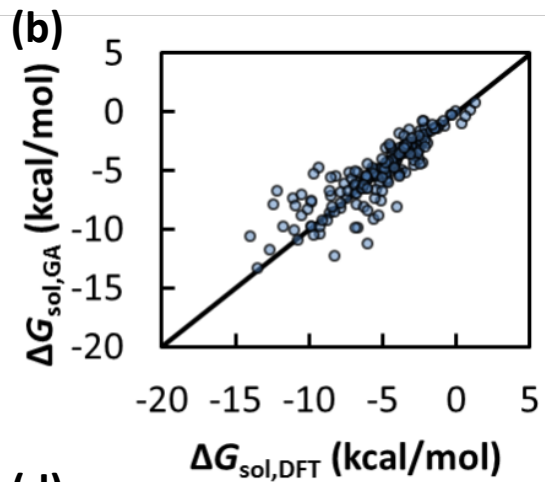

(d)

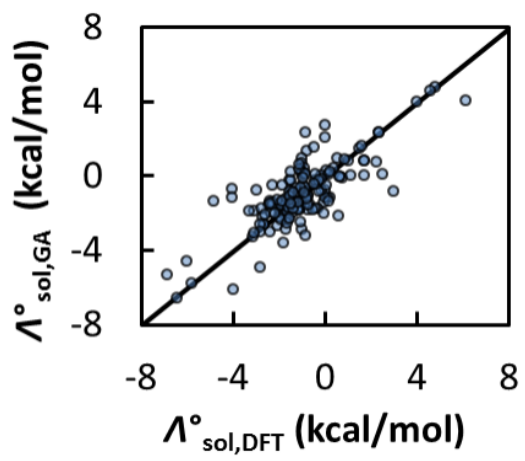

Figure 4. Parity plot between 10-fold cross-validation computed prediction and DFT data for (a) Gibbs free energy

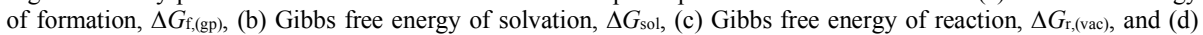
the change of reaction energies upon solvation, $\Lambda_{\mathrm{sol}}$, as defined in Eq.(14), and (15), 151 reactions of the ethanol reaction network are considered (see SI for the detail).

Table 2. Mean and maximum (Max) absolute errors (AEs) and root meat square (RMSE) for 10-fold crossvalidation of thermodynamic properties in $\mathrm{kcal} / \mathrm{mol}$.

\section{Properties MeanAE MaxAE RMSE}

$\begin{array}{llll}\Delta G_{\mathrm{f},(\mathrm{gp})} & 3.3 & 16.5 & 4.8 \\ \Delta G_{\mathrm{f},(\mathrm{aq})} & 3.3 & 17.5 & 4.8 \\ \Delta G_{\mathrm{sol}} & 1.0 & 5.4 & 1.6 \\ \Delta G_{\mathrm{r},(\mathrm{gp})} & 2.9 & 13.8 & 4.0\end{array}$




$\begin{array}{llll}\Delta G_{\mathrm{r},(\mathrm{aq})} & 2.8 & 15.1 & 3.9 \\ \Lambda_{\text {sol }} & 0.9 & 3.8 & 1.2\end{array}$

We also assess the model's predictive ability for the (151) reaction free energies in the ethanol steam reforming reaction network. ${ }^{87}$ Specifically, we compare the Gibbs free energy of reaction

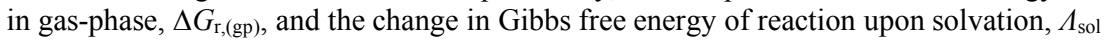

Figure $4 \mathrm{c}$ and $\mathrm{d}$ show the parity plot of the group additivity computed values vs. the DFTderived $\Delta G_{\mathrm{r},(\mathrm{gp})}$ and $\Lambda_{\text {sol. }}$. The MeanAE and MaxAE for $\Delta G_{\mathrm{r},(\mathrm{gp})}$ are 2.9 and $13.8 \mathrm{kcal} / \mathrm{mol}$, which

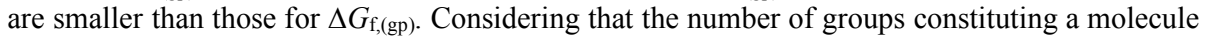
is typically larger than the number of groups changing in a reaction, the variance is likely smaller for the reaction energy, explaining the smaller error. The MeanAE and MaxAE for $\Lambda_{\text {sol }}$ are reasonable at 0.9 and $3.8 \mathrm{kcal} / \mathrm{mol}$, respectively. However, as can be seen in Figure $4 \mathrm{~d}$, the parity plot is not perfect, i.e., the predicted change of solvation energies along a reaction is not very well correlated to the DFT data. One of the main issues is the evidenced reorientation of OHgroups discussed above: in the GA, the orientation of the $\mathrm{OH}$ group is not accounted for, implying that these subtle effects cannot be investigated by the present group additivity scheme. However, since the Gibbs reaction energy prediction is rather accurate, the main goal of the GA is still achieved: rapid prediction of various reaction energies at a solvated metal surface.

For a further assessment of the quality of the solvation free energy group additivity, we compare the trends we obtained in Figure 3 with the DFT calculations with the trends we obtain using our group additivity scheme (Figure S3 in SI). Overall, the solvation free energy group additivity captures the trend very well. The mean and median between the DFT and the group additivity are close, signifying that our model captures the general dependency on the reaction type and functional groups. However, the boxes and whiskers are tighter for the model than the DFT (i.e., variance is not captured by the model). Especially, the model computed $\Lambda_{\text {sol }}$ for $\mathrm{O}-\mathrm{H}$ scission and $\Delta G_{\text {sol }}$ for Hydroxyls have significantly lower variance than the DFT-computed values. Future work will be based on information from explicit water simulations and include heterolytic bond breakings involving protons, which may be important in biomass conversion. These improvements would, ultimately, allow to investigate the $\mathrm{pH}$ dependence of reaction schemes at the group additivity level.

\section{CONCLUSIONS}

The impact of an implicit solvent on adsorption of alcohols on the Pt(111) surface has first been investigated by DFT computations. We evidenced only minor changes in the geometries upon solvation, which the re-orientation of an $\mathrm{O}-\mathrm{H}$ bond pointing towards the surface in vacuum and being more stable pointing into the solvent being the rare exception. Examination of the ethanol reforming reaction network reveals, however, that equilibrium constants of surface reactions change significantly in solvent depending on the reaction type. In aqueous environment, C-H scission is slightly favored as the oxygen group of the oxygenate is raised towards bulk water, whereas $\mathrm{O}-\mathrm{H}$ scission is thermodynamically disfavored as the oxygen binds to the surface which decreases the oxygen-water interaction. In order to cut down the computational expense of such studies, we have developed a simple group additivity scheme for the Gibbs free energy of linear alcohols at the Pt(111) water interface by computing the thermodynamic properties of 200 adsorbates and gaseous species using DFT and an implicit solvent. The 10-fold cross-validation yields a MeanAE for the Gibbs free energy of formation 
and the Gibbs free energy of solvation of 3.3 and $1.0 \mathrm{kcal} / \mathrm{mol}$, respectively, and smaller error for reaction energies $(\mathrm{MeanAE}=2.8 \mathrm{kcal} / \mathrm{mol}$ ). Despite severe approximations regarding the entropy of adsorption, this development allows addressing large and complex reaction networks, such as hydro-deoxygenations of poly-ols such as glycerol, erythritol or even sorbitol in order to narrow down the most likely reaction routes, which then can be studied by DFT computations. Furthermore, the corresponding solvent effects can be improved in order to refine the subtle enthalpy-entropy balance at the solid-liquid interface.

\section{- ASSOCIATED CONTENT}

We have built a python package to find group additivity descriptors and compute thermodynamic properties, available at https://github.com/vlachosgroup.

\section{Supporting Information}

The supporting information includes the figures, groups and data set information. The supporting information is available free of charge on the ACS Publications website at DOI: 10.1021/XXXX.

Supplementary figures for assumptions made, PCM method validation, and the ethanol reforming reaction network information. (PDF)

DFT energies and vibrational frequencies for reference and training set, as well as their groups, and group values. (XLSX)

DFT structures (xyz format) for the data set. (ZIP)

\section{- AUTHOR INFORMATION}

\section{Corresponding Author}

*E-mail: vlachos@udel.edu. Tel. 1-302-831-2830.

*E-mail: stephan.steinmann@ens-lyon.fr. Tel. 0033-472-72-8155.

\section{Notes}

The authors declare no competing financial interest.

\section{- ACKNOWLEDGEMENTS}

G. G. is grateful to Dr. Glen R. Jenness for the paper writing improvement. We acknowledge Angela Norton for performing COSMO-SAC calculations (Figure S2 in SI). G. G. developed the group additivity model, B. S. performed DFT calculations, D. G. V., P. S., C. M., and S. N. S. conceptualized the research, and advised the research direction. This research was supported by the NSF under grant number CHE-1415828. This work benefited from the support of the project MuSiC ANR-14-CE06-0030 of the French National Research Agency (ANR). This work was granted access to the HPC resources of CINES and IDRIS under the allocation A0010810119 and x2015080609 made by GENCI. Computational resources from the Pôle Scientifique de Modélisation Numérique (PSMN) at ENS Lyon are greatly acknowledged as well. 


\section{REFERENCES}

(1) Huber, G. W.; Shabaker, J. W.; Dumesic, J. A. Raney Ni-Sn Catalyst for $\mathrm{H}_{2}$ Production from Biomass-Derived Hydrocarbons. Science 2003, 300, 2075-2077.

(2) Dickerson, T.; Soria, J. Catalytic Fast Pyrolysis: A Review. Energies 2013, 6, 514-538.

(3) Laurent, E.; Delmon, B. Influence of Water in the Deactivation of a Sulfided NiMo $\mathrm{Al}_{2} \mathrm{O}_{3}$ Catalyst During Hydrodeoxygenation. J. Catal. 1994, 146, 281-291.

(4) Beerthuis, R.; Rothenberg, G.; Shiju, N. R. Catalytic Routes Towards Acrylic Acid, Adipic Acid and $\varepsilon$-Caprolactam Starting from Biorenewables. Green Chem. 2015, 17, 1341-1361.

(5) Yan, N.; Zhao, C.; Luo, C.; Dyson, P. J.; Liu, H.; Kou, Y. One-Step Conversion of Cellobiose to C6-Alcohols Using a Ruthenium Nanocluster Catalyst. J. Am. Chem. Soc. 2006, 128, 8714-8715.

(6) Xiao, C.-x.; Cai, Z.-p.; Wang, T.; Kou, Y.; Yan, N. Aqueous-Phase Fischer-Tropsch Synthesis with a Ruthenium Nanocluster Catalyst. Angew. Chem. Int. Ed. 2008, 47, 746749.

(7) Cortright, R. D.; Davda, R. R.; Dumesic, J. A. Hydrogen from Catalytic Reforming of Biomass-Derived Hydrocarbons in Liquid Water. Nature 2002, 418, 964-967.

(8) Lee, J.; Xu, Y.; Huber, G. W. High-Throughput Screening of Monometallic Catalysts for Aqueous-Phase Hydrogenation of Biomass-Derived Oxygenates. Appl. Catal., B 2013, 140-141, 98-107.

(9) Wang, Y.; Yao, J.; Li, H.; Su, D.; Antonietti, M. Highly Selective Hydrogenation of Phenol and Derivatives over a Pd@Carbon Nitride Catalyst in Aqueous Media. J. Am. Chem. Soc. 2011, 133, 2362-2365.

(10) Wertz, D. H. Relationship between the Gas-Phase Entropies of Molecules and Their Entropies of Solvation in Water and 1-Octanol. J. Am. Chem. Soc. 1980, 102, 5316-5322.

(11) Yoon, Y.; Rousseau, R.; Weber, R. S.; Mei, D.; Lercher, J. A. First-Principles Study of Phenol Hydrogenation on Pt and Ni Catalysts in Aqueous Phase. J. Am. Chem. Soc. 2014, 136, 10287-10298.

(12) Behtash, S.; Lu, J.; Mamun, O.; Williams, C. T.; Monnier, J. R.; Heyden, A. Solvation Effects in the Hydrodeoxygenation of Propanoic Acid over a Model Pd(211) Catalyst. $J$. Chem. Phys. C 2016, 120, 2724-2736.

(13) Behtash, S.; Lu, J.; Walker, E.; Mamun, O.; Heyden, A. Solvent Effects in the Liquid Phase Hydrodeoxygenation of Methyl Propionate over a $\operatorname{Pd}\left(\begin{array}{lll}1 & 1 & 1\end{array}\right)$ Catalyst Model. $J$. Catal. 2016, 333, 171-183.

(14) Behtash, S.; Lu, J.; Faheem, M.; Heyden, A. Solvent Effects on the Hydrodeoxygenation of Propanoic Acid over Pd(111) Model Surfaces. Green Chem. 2014, 16, 605-616.

(15) Desai, S. K.; Neurock, M. First-Principles Study of the Role of Solvent in the Dissociation of Water over a Pt-Ru Alloy. Phys. Rev. B 2003, 68, 075420.

(16) Steinmann, S. N.; Sautet, P.; Michel, C. Solvation Free Energies for Periodic Surfaces: Comparison of Implicit and Explicit Solvation Models. Phys. Chem. Chem. Phys 2016, 18, 31850-31861.

(17) Taylor, C. D.; Neurock, M. Theoretical Insights into the Structure and Reactivity of the Aqueous/Metal Interface. Curr. Opin. Solid State Mater. Sci. 2005, 9, 49-65. 
(18) Akpa, B. S.; D’Agostino, C.; Gladden, L. F.; Hindle, K.; Manyar, H.; McGregor, J.; Li, R.; Neurock, M.; Sinha, N.; Stitt, E. H.; Weber, D.; Zeitler, J. A.; Rooney, D. W. Solvent Effects in the Hydrogenation of 2-Butanone. J. Catal. 2012, 289, 30-41.

(19) Liu, J.; Cao, X.-M.; Hu, P. Density Functional Theory Study on the Activation of Molecular Oxygen on a Stepped Gold Surface in an Aqueous Environment: a New Approach for Simulating Reactions in Solution. Phys. Chem. Chem. Phys 2014, 16, 41764185.

(20) Carter, E. A.; Ciccotti, G.; Hynes, J. T.; Kapral, R. Constrained Reaction Coordinate Dynamics for the Simulation of Rare Events. Chem. Phys. Lett. 1989, 156, 472-477.

(21) Sprik, M.; Ciccotti, G. Free Energy from Constrained Molecular Dynamics. J. Chem. Phys. 1998, 109, 7737-7744.

(22) Jindal, G.; Warshel, A. Exploring the Dependence of QM/MM Calculations of Enzyme Catalysis on the Size of the QM Region. J. Chem. Phys. B 2016, 120, 9913-9921.

(23) Bellarosa, L.; García-Muelas, R.; Revilla-López, G.; López, N. Diversity at the WaterMetal Interface: Metal, Water Thickness, and Confinement Effects. ACS Cent. Sci. 2016, $2,109-116$

(24) Desai, S. K.; Pallassana, V.; Neurock, M. A Periodic Density Functional Theory Analysis of the Effect of Water Molecules on Deprotonation of Acetic Acid over Pd(111). J. Chem. Phys. B 2001, 105, 9171-9182.

(25) Michel, C.; Zaffran, J.; Ruppert, A. M.; Matras-Michalska, J.; Jedrzejczyk, M.; Grams, J.; Sautet, P. Role of Water in Metal Catalyst Performance for Ketone Hydrogenation: a Joint Experimental and Theoretical Study on Levulinic Acid Conversion into GammaValerolactone. Chem. Commun. 2014, 50, 12450-12453.

(26) Cao, D.; Lu, G. Q.; Wieckowski, A.; Wasileski, S. A.; Neurock, M. Mechanisms of Methanol Decomposition on Platinum: A Combined Experimental and ab Initio Approach. J. Chem. Phys. B 2005, 109, 11622-11633.

(27) Zope, B. N.; Hibbitts, D. D.; Neurock, M.; Davis, R. J. Reactivity of the Gold/Water Interface During Selective Oxidation Catalysis. Science 2010, 330, 74-78.

(28) Faheem, M.; Heyden, A. Hybrid Quantum Mechanics/Molecular Mechanics Solvation Scheme for Computing Free Energies of Reactions at Metal-Water Interfaces. J. Chem. Theory Comput. 2014, 10, 3354-3368.

(29) Mathew, K.; Sundararaman, R.; Letchworth-Weaver, K.; Arias, T. A.; Hennig, R. G. Implicit Solvation Model for Density-Functional Study of Nanocrystal Surfaces and Reaction Pathways. J. Chem. Phys. 2014, 140, 084106.

(30) Faheem, M.; Suthirakun, S.; Heyden, A. New Implicit Solvation Scheme for Solid Surfaces. J. Chem. Phys. C 2012, 116, 22458-22462.

(31) Garcia-Ratés, M.; López, N. Multigrid-Based Methodology for Implicit Solvation Models in Periodic DFT. J. Chem. Theory Comput. 2016, 12, 1331-1341.

(32) Pliego, J. R.; Riveros, J. M. The Cluster-Continuum Model for the Calculation of the Solvation Free Energy of Ionic Species. J. Chem. Phys. A 2001, 105, 7241-7247.

(33) Asthagiri, D.; Pratt, L. R.; Ashbaugh, H. S. Absolute Hydration Free Energies of Ions, Ion-Water Clusters, and Quasichemical Theory. J. Chem. Phys. 2003, 119, 2702-2708.

(34) Bryantsev, V. S.; Diallo, M. S.; Goddard Iii, W. A. Calculation of Solvation Free Energies of Charged Solutes Using Mixed Cluster/Continuum Models. J. Chem. Phys. B 2008, 112, 9709-9719. 
(35) Wang, H.-F.; Liu, Z.-P. Formic Acid Oxidation at Pt/H2O Interface from Periodic DFT Calculations Integrated with a Continuum Solvation Model. J. Chem. Phys. C 2009, 113, 17502-17508.

(36) Steinmann, S. N.; Michel, C.; Schwiedernoch, R.; Sautet, P. Impacts of Electrode Potentials and Solvents on the Electroreduction of $\mathrm{CO}_{2}$ : a Comparison of Theoretical Approaches. Phys. Chem. Chem. Phys 2015, 17, 13949-13963.

(37) Wang, P.; Steinmann, S. N.; Fu, G.; Michel, C.; Sautet, P. Key Role of Anionic Doping for $\mathrm{H}_{2}$ Production from Formic Acid on Pd(111). ACS Catal. 2017, 7, 1955-1959.

(38) Sutton, J. E.; Vlachos, D. G. Building Large Microkinetic Models with First-Principles' Accuracy at Reduced Computational Cost. Chem. Eng. Sci. 2015, 121, 190-199.

(39) Benson, S. W.; Buss, J. H. Additivity Rules for the Estimation of Molecular Properties. Thermodynamic Properties. J. Chem. Phys. 1958, 29, 546-572.

(40) Eigenmann, H. K.; Golden, D. M.; Benson, S. W. Revised Group Additivity Parameters for the Enthalpies of Formation of Oxygen-Containing Organic Compounds. J. Chem. Phys. 1973, 77, 1687-1691.

(41) Stein, S. E.; Golden, D. M.; Benson, S. W. Predictive Scheme for Thermochemical Properties of Polycyclic Aromatic Hydrocarbons. J. Chem. Phys. 1977, 81, 314-317.

(42) Benson, S. W. Thermochemistry and Kinetics of Sulfur-Containing Molecules and Radicals. Chem. Rev. 1978, 78, 23-35.

(43) Willems, P. A.; Froment, G. F. Kinetic Modeling of the Thermal Cracking of Hydrocarbons. 1. Calculation of Frequency Factors. Ind. Eng. Chem. Res. 1988, 27, 1959-1966.

(44) Willems, P. A.; Froment, G. F. Kinetic Modeling of the Thermal Cracking of Hydrocarbons. 2. Calculation of Activation Energies. Ind. Eng. Chem. Res. 1988, 27, 1966-1971.

(45) Martinis, J. M.; Froment, G. F. Alkylation on Solid Acids. Part 2. Single-Event Kinetic Modeling. Ind. Eng. Chem. Res. 2006, 45, 954-967.

(46) Luria, M.; Benson, S. W. Heat Capacities of Liquid Hydrocarbons. Estimation of Heat Capacities at Constant Pressure as a Temperature Function, Using Additivity Rules. $J$. Chem. Eng. Data 1977, 22, 90-100.

(47) Constantinou, L.; Gani, R.; O'Connell, J. P. Estimation of the Acentric Factor and the Liquid Molar Volume at 298 K Using a New Group Contribution Method. Fluid Phase Equilib. 1995, 103, 11-22.

(48) Constantinou, L.; Gani, R. New Group Contribution Method for Estimating Properties of Pure Compounds. AIChE J. 1994, 40, 1697-1710.

(49) Wu, D. T. Proceedings of the Fourth International Conference: Prediction of Viscosities of Liquid Mixtures by a Group Contribution Method. Fluid Phase Equilib. 1986, 30, 149156.

(50) Ihmels, E. C.; Gmehling, J. Extension and Revision of the Group Contribution Method GCVOL for the Prediction of Pure Compound Liquid Densities. Ind. Eng. Chem. Res. 2003, 42, 408-412.

(51) Abrams, D. S.; Prausnitz, J. M. Statistical Thermodynamics of Liquid Mixtures: A New Expression for the Excess Gibbs Energy of Partly or Completely Miscible Systems. AIChE J. 1975, 21, 116-128.

(52) Fredenslund, A.; Jones, R. L.; Prausnitz, J. M. Group-Contribution Estimation of Activity Coefficients in Nonideal Liquid Mixtures. AIChE J. 1975, 21, 1086-1099. 
(53) Chapman, W. G.; Gubbins, K. E.; Jackson, G.; Radosz, M. New Reference Equation of State for Associating Liquids. Ind. Eng. Chem. Res. 1990, 29, 1709-1721.

(54) Lymperiadis, A.; Adjiman, C. S.; Galindo, A.; Jackson, G. A Group Contribution Method for Associating Chain Molecules Based on the Statistical Associating Fluid Theory (SAFT- $\gamma$ ). J. Chem. Phys. 2007, 127, 234903.

(55) Kua, J.; Faglioni, F.; Goddard, W. A. Thermochemistry for Hydrocarbon Intermediates Chemisorbed on Metal Surfaces: $\mathrm{CH}_{\mathrm{n}-\mathrm{m}}\left(\mathrm{CH}_{3}\right)_{\mathrm{m}}$ with $\mathrm{n}=1,2,3$ and $\mathrm{m} \leq \mathrm{n}$ on Pt, Ir, Os, Pd, Rh, and Ru. J. Am. Chem. Soc. 2000, 122, 2309-2321.

(56) Salciccioli, M.; Edie, S. M.; Vlachos, D. G. Adsorption of Acid, Ester, and Ether Functional Groups on Pt: Fast Prediction of Thermochemical Properties of Adsorbed Oxygenates via DFT-Based Group Additivity Methods. J. Chem. Phys. C 2012, 116, $1873-1886$.

(57) Vorotnikov, V.; Wang, S.; Vlachos, D. G. Group Additivity for Estimating Thermochemical Properties of Furanic Compounds on Pd(111). Ind. Eng. Chem. Res. 2014, 53, 11929-11938.

(58) Gu, G. H.; Vlachos, D. G. Group Additivity for Thermochemical Property Estimation of Lignin Monomers on Pt(111). J. Chem. Phys. C 2016, 120, 19234-19241.

(59) Salciccioli, M.; Chen, Y.; Vlachos, D. G. Density Functional Theory-Derived Group Additivity and Linear Scaling Methods for Prediction of Oxygenate Stability on Metal Catalysts: Adsorption of Open-Ring Alcohol and Polyol Dehydrogenation Intermediates on Pt-Based Metals. J. Chem. Phys. C 2010, 114, 20155-20166.

(60) Vorotnikov, V.; Vlachos, D. G. Group Additivity and Modified Linear Scaling Relations for Estimating Surface Thermochemistry on Transition Metal Surfaces: Application to Furanics. J. Chem. Phys. C 2015, 119, 10417-10426.

(61) Kresse, G.; Hafner, J. Ab initio Molecular Dynamics for Liquid Metals. Phys. Rev. B 1993, 47, 558-561.

(62) Perdew, J. P.; Burke, K.; Ernzerhof, M. Generalized Gradient Approximation Made Simple. Phys. Rev. Lett. 1996, 77, 3865-3868.

(63) Steinmann, S. N.; Corminboeuf, C. Comprehensive Benchmarking of a DensityDependent Dispersion Correction. J. Chem. Theory Comput. 2011, 7, 3567-3577.

(64) Steinmann, S. N.; Corminboeuf, C. A Generalized-Gradient Approximation Exchange Hole Model for Dispersion Coefficients. J. Chem. Phys. 2011, 134, 044117.

(65) Blöchl, P. E. Projector Augmented-Wave Method. Phys. Rev. B 1994, 50, 17953-17979.

(66) Kresse, G.; Joubert, D. From Ultrasoft Pseudopotentials to the Projector AugmentedWave Method. Phys. Rev. B 1999, 59, 1758-1775.

(67) Fishman, M.; Zhuang, H. L.; Mathew, K.; Dirschka, W.; Hennig, R. G. Accuracy of Exchange-Correlation Functionals and Effect of Solvation on the Surface Energy of Copper. Phys. Rev. B 2013, 87, 245402.

(68) Ben-Naim, A. Solvation Thermodynamics. Springer US: New York, 1987.

(69) Ben-Naim, A. Statistical Thermodynamics for Chemists and Biochemists. Springer US: New York, 1992.

(70) Cooper, J.; Ziegler, T. A Density Functional Study of SN2 Substitution at Square-Planar Platinum(II) Complexes. Inorganic Chemistry 2002, 41, 6614-6622.

(71) Golze, D.; Iannuzzi, M.; Nguyen, M.-T.; Passerone, D.; Hutter, J. Simulation of Adsorption Processes at Metallic Interfaces: An Image Charge Augmented QM/MM Approach. J. Chem. Theory Comput. 2013, 9, 5086-5097. 
(72) Schiros, T.; Andersson, K. J.; Pettersson, L. G. M.; Nilsson, A.; Ogasawara, H. Chemical Bonding of Water to Metal Surfaces Studied with Core-Level Spectroscopies. $J$. Electron. Spectrosc. Relat. Phenom. 2010, 177, 85-98.

(73) Limmer, D. T.; Willard, A. P.; Madden, P.; Chandler, D. Hydration of Metal Surfaces Can be Dynamically Heterogeneous and Hydrophobic. Proc. Natl. Acad. Sci. 2013, 110, 4200-4205.

(74) Sakong, S.; Forster-Tonigold, K.; Groß, A. The Structure of Water at a $\operatorname{Pt}(111)$ Electrode and the Potential of Zero Charge Studied from First Principles. J. Chem. Phys. 2016, 144, 194701.

(75) Carlsson, J.; Åqvist, J. Absolute and Relative Entropies from Computer Simulation with Applications to Ligand Binding. J. Chem. Phys. B 2005, 109, 6448-6456.

(76) Natarajan, S. K.; Behler, J. Neural Network Molecular Dynamics Simulations of SolidLiquid Interfaces: Water at Low-Index Copper Surfaces. Phys. Chem. Chem. Phys 2016, $18,28704-28725$.

(77) Kelly, E.; Seth, M.; Ziegler, T. Calculation of Free Energy Profiles for Elementary Bimolecular Reactions by ab Initio Molecular Dynamics: Sampling Methods and Thermostat Considerations. J. Chem. Phys. A 2004, 108, 2167-2180.

(78) Price, D. L.; Halley, J. W. Molecular Dynamics, Density Functional Theory of the MetalElectrolyte Interface. J. Chem. Phys. 1995, 102, 6603-6612.

(79) Lee, M.-S.; Peter McGrail, B.; Rousseau, R.; Glezakou, V.-A. Structure, Dynamics and Stability of Water/scCO2/Mineral Interfaces from ab initio Molecular Dynamics Simulations. Sci. Rep. 2015, 5, 14857.

(80) Cheng, T.; Xiao, H.; Goddard, W. A. Full Atomistic Reaction Mechanism with Kinetics for $\mathrm{CO}$ Reduction on $\mathrm{Cu}(100)$ from ab initio Molecular Dynamics Free-Energy Calculations at 298 K. Proc. Natl. Acad. Sci. 2017, 114, 1795-1800.

(81) Cantu, D. C.; Wang, Y.-G.; Yoon, Y.; Glezakou, V.-A.; Rousseau, R.; Weber, R. S. Heterogeneous Catalysis in Complex, Condensed Reaction Media. Catal. Today 2017, 289, 231-236.

(82) Schravendijk, P.; van der Vegt, N.; Delle Site, L.; Kremer, K. Dual-Scale Modeling of Benzene Adsorption onto $\mathrm{Ni}(111)$ and $\mathrm{Au}(111)$ Surfaces in Explicit Water. ChemPhysChem 2005, 6, 1866-1871.

(83) Li, X.; Ågren, H. Molecular Dynamics Simulations Using a Capacitance-Polarizability Force Field. J. Chem. Phys. C 2015, 119, 19430-19437.

(84) Spohr, E. Computer simulation of the water/platinum interface. J. Chem. Phys. 1989, 93, 6171-6180.

(85) Bengio, Y.; Grandvalet, Y. No Unbiased Estimator of the Variance of K-Fold CrossValidation. J. Mach. Learn. Res. 2004, 5, 1089-1105.

(86) Kohavi, R. A Study of Cross-Validation and Bootstrap for Accuracy Estimation and Model Selection. In Proceedings of the 14th international joint conference on Artificial intelligence - Volume 2, Morgan Kaufmann Publishers Inc.: Montreal, Quebec, Canada, 1995; pp 1137-1143.

(87) Sutton, J. E.; Panagiotopoulou, P.; Verykios, X. E.; Vlachos, D. G. Combined DFT, Microkinetic, and Experimental Study of Ethanol Steam Reforming on Pt. J. Phys. Chem. C 2013, 117, 4691-4706.

(88) Rangarajan, S.; Bhan, A.; Daoutidis, P. Language-oriented rule-based reaction network generation and analysis: Applications of RING. Chem. Eng. Sci. 2012, 46, 141-152. 
(89) Rangarajan, S.; Bhan, A.; Daoutidis, P. Language-oriented rule-based reaction network generation and analysis: Description of RING. Chem. Eng. Sci. 2012, 45, 114-123.

(90) Kabsch, W. A Solution for the Best Rotation to Relate Two Sets of Vectors. Acta Crystallogr., Sect. A: Gound. Crystallogr. 1976, 32, 922-923.

(91) Walker, M. W.; Shao, L.; Volz, R. A. Estimating 3-D Location Parameters Using Dual Number Quaternions. CVGIP: Image Understanding 1991, 54, 358-367.

(92) Kromann, J. C.; Steinmann, C.; larsbratholm; aandi; Lauritzen, K. P. RMSD: Small Release Update. 10.5281/zenodo.46697.

(93) Zaffran, J.; Michel, C.; Delbecq, F.; Sautet, P. Towards More Accurate Prediction of Activation Energies for Polyalcohol Dehydrogenation on Transition Metal Catalysts in Water. Catal. Sci. Tech. 2016, 6, 6615-6624.

(94) Garcia-Ratés, M.; García-Muelas, R.; López, N. Solvation Effects on Methanol Decomposition on $\operatorname{Pd}(111), \operatorname{Pt}(111)$, and Ru(0001). J. Phys. Chem. C 2017, 121, 1380313809.

(95) Salciccioli, M.; Stamatakis, M.; Caratzoulas, S.; Vlachos, D. G. A Review of Multiscale Modeling of Metal-Catalyzed Reactions: Mechanism Development for Complexity and Emergent Behavior. Chem. Eng. Sci. 2011, 66, 4319-4355.

(96) Bader, R. F. W.; Bayles, D. Properties of Atoms in Molecules: Group Additivity. $J$. Chem. Phys. A 2000, 104, 5579-5589. 


\section{TOC Graphic}

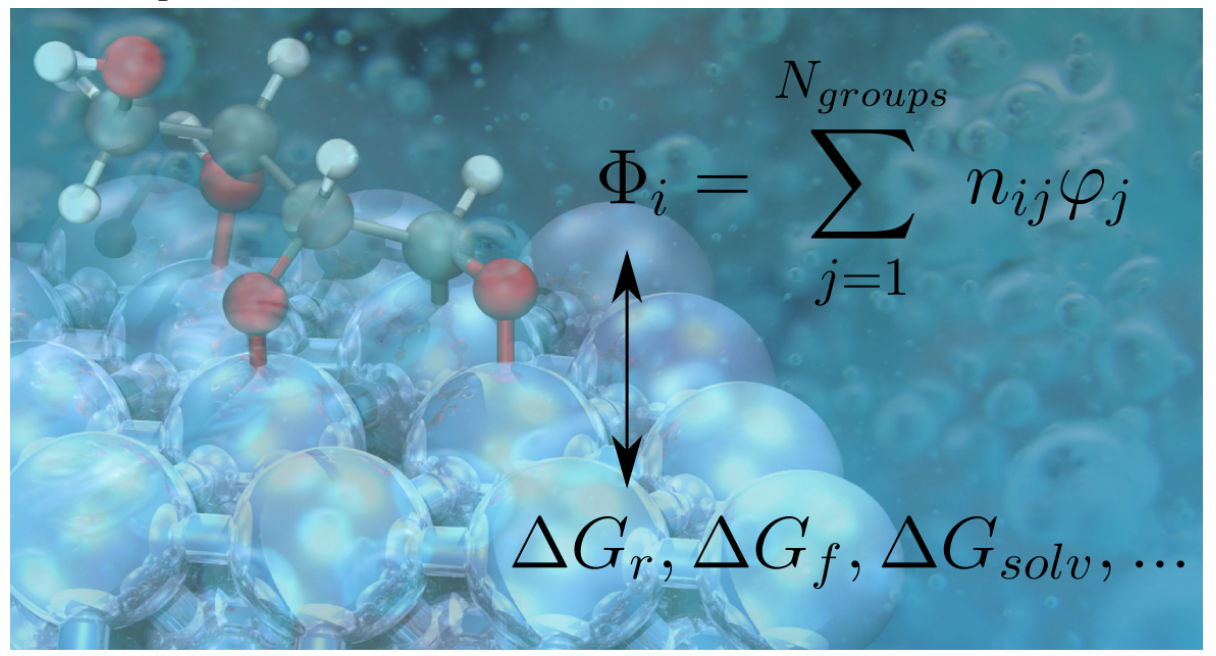

